\title{
Treatment of dyslipidemia in patients with type 2 diabetes
}

\author{
Krishnaswami Vijayaraghavan
}

\begin{abstract}
Type 2 diabetes is associated with significant cardiovascular morbidity and mortality. Although low-density lipoprotein cholesterol levels may be normal in patients with type 2 diabetes, insulin resistance drives a number of changes in lipid metabolism and lipoprotein composition that render low-density lipoprotein cholesterol and other lipoproteins more pathogenic than species found in patients without type 2 diabetes. Dyslipidemia, which affects almost 50\% of patients with type 2 diabetes, is a cardiovascular risk factor characterized by elevated triglyceride levels, low high-density lipoprotein cholesterol levels, and a preponderance of small, dense, low-density lipoprotein particles. Early, aggressive pharmacological management is advocated to reduce low-density lipoprotein cholesterol levels, regardless of baseline levels. A number of lipid-lowering agents, including statins, fibrates, niacin, and bile acid sequestrants, are available to target normalization of the entire lipid profile. Despite use of combination and high-dose lipid-lowering agents, many patients with type 2 diabetes do not achieve lipid targets. This review outlines the characteristics and prevalence of dyslipidemia in patients with type 2 diabetes and discusses strategies that may reduce the risk of cardiovascular disease in this population.
\end{abstract}

\section{Introduction}

Type 2 diabetes affects approximately 24 million individuals in the United States [1] and is associated with significant morbidity and mortality due to cardiovascular complications [2]. The incidence of cardiovascular disease (CVD) is more common in patients with type 2 diabetes than in the general population [3]. Dyslipidemia, an established risk factor for CVD, is strikingly common in patients with type 2 diabetes, affecting almost $50 \%$ of this population [4]. In addition to hyperglycemia and hypertension, dyslipidemia is a modifiable CVD risk factor that remains largely uncontrolled in patients with type 2 diabetes [4].

Hyperglycemia increases the risk of microvascular complications [5], while dyslipidemia is a major risk factor for macrovascular complications in patients with type 2 diabetes [6,7]. Elevated low-density lipoprotein cholesterol (LDL-C) is a major risk factor for CVD [6]. As such, management of LDL-C is the primary goal of therapy for diabetic dyslipidemia [8-10]. Furthermore, type 2 diabetes increases the risk of CVD mortality independent of LDL-C levels, adding to the greater

Correspondence: kvijaymd@gmail.com

Cardiovascular Division, Scottsdale Healthcare Research Institute, Scottsdale, AZ, USA overall cardiovascular risk in this population [11]. Therefore, aggressive lipid treatment goals have been recommended for patients with type 2 diabetes (Table 1) [8-10,12]. As the prevalence of type 2 diabetes increases in the United States, prevention of CVD is becoming an increasingly urgent public health concern, requiring aggressive management of the entire lipid profile [8]. This review outlines the characteristics and prevalence of dyslipidemia in patients with type 2 diabetes and discusses strategies that may reduce the risk of CVD in this population.

\section{Characteristics and mechanisms of lipoprotein abnormalities in type $\mathbf{2}$ diabetes}

The hallmarks of type 2 diabetes are hyperglycemia, insulin resistance, and insulin deficiency, and it is increasingly recognized that insulin resistance contributes to the characteristic dyslipidemia associated with type 2 diabetes [13]. Disturbance of lipid metabolism appears to be an early event in the development of type 2 diabetes, potentially preceding the disease by several years [14]. In addition, the different components of diabetic dyslipidemia (plasma lipid and lipoprotein abnormalities) are believed to be metabolically linked $[13,15]$. The dyslipidemia associated with insulin resistance (also referred to as atherogenic

\section{Biomed Central}


Table 1 Low-density Lipoprotein Cholesterol (LDL-C) and Non-HDL-C Goals for Patients in Different CVD Risk Categories from the Adult Treatment Panel III of the National Cholesterol Education Program [12,30]

\begin{tabular}{lcc}
\hline Risk Category & & Goals (mg/dL) \\
\cline { 2 - 3 } CVD + T2DM (CVD risk equivalent) & Primary target: LDL-C & Secondary target: Non-HDL-C \\
\hline CVD or T2DM ${ }^{\ddagger}$ & $<70$ & $<100$ \\
\hline$\geq 2$ risk factors (not CVD risk equivalents) & $<100$ & $<130$ \\
\hline $0-1$ risk factor (not a CVD risk equivalent) & $<130$ & $<160$ \\
\hline
\end{tabular}

CVD, cardiovascular disease; HDL-C, high-density lipoprotein cholesterol; T2DM, type 2 diabetes mellitus; non-HDL-C = LDL-C + very-low-density lipoprotein cholesterol (VLDL-C) or total cholesterol - HDL-C.

*In addition to reduction of LDL-C to a goal of $<70 \mathrm{mg} / \mathrm{dL}$ as an option in very high-risk patients with overt CVD (level of evidence B), additional American Diabetes Association (ADA) recommendations are the reduction of LDL-C by $30 \%-40 \%$ in all patients with diabetes and overt CVD, regardless of baseline LDL-C levels (level of evidence A); lower triglycerides to $<150 \mathrm{mg} / \mathrm{dL}$ and raise $\mathrm{HDL}-\mathrm{C}$ to $>40 \mathrm{mg} / \mathrm{dL}$, with the option of $>50 \mathrm{mg} / \mathrm{dL}$ in women (level of evidence C) [10].

${ }^{\dagger}$ In addition to the reduction of LDL-C to $<100 \mathrm{mg} / \mathrm{dL}$ as the primary therapeutic goal (level of evidence A), the ADA recommends that LDL-C be reduced by $30 \%-40 \%$ in all patients with diabetes $>40$ years of age without overt CVD, regardless of baseline LDL-C levels (level of evidence C) [10].

$\ddagger$ Non-HDL-C is a secondary target of therapy in patients with high serum triglycerides ( $\geq 200 \mathrm{mg} / \mathrm{dL}$ ) [30].

dyslipidemia) is characterized by moderately increased triglyceride (TG) levels carried in very-low-density lipoprotein (VLDL) particles, reduced high-density lipoprotein cholesterol (HDL-C) levels carried in small HDL particles, and LDL-C levels that do not differ substantially from those of individuals without type 2 diabetes (Figure 1) [13,15-17]. In addition, TG-rich lipoproteins (after eating), remnant lipoproteins, apolipoprotein B 100 (ApoB), and small, dense HDL particles have also been shown to be increased in patients with type 2 diabetes [18]. In patients with type 2 diabetes, LDL particles are small and dense, carrying less cholesterol per particle; therefore, at any given LDL-C concentration, there are more LDL particles present in an individual with type 2 diabetes relative to an

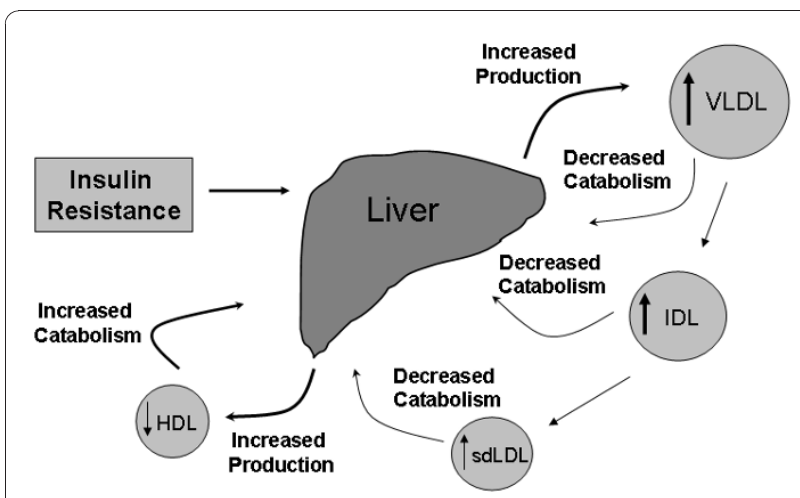

Figure 1 Atherogenic dyslipidemia and changes in lipoprotein metabolism associated with type 2 diabetes mellitus [51]. Insulin resistance is associated with enhanced production of verylow-density lipoprotein (VLDL); a reduction in the catabolic rate of intermediate-density lipoprotein (IDL) and small, dense low-density lipoprotein (sdLDL); increased production of high-density lipoprotein (HDL) outweighed by increased catabolism. Adapted with permission from Adiels et al, Overproduction of very low-density lipoproteins is the hallmark of the dyslipidemia in the metabolic syndrome. Arterioscler Thromb Vasc Biol 28(7): 1225-1236 (2008) [14] individual without the disease, which may make the LDL$\mathrm{C}$ level a misleading measure of risk in patients with type 2 diabetes [8].

The association between hyperglycemia and microvascular complications in type 2 diabetes is unequivocal $[5,19]$. However, dyslipidemia may correlate more directly with cardiovascular complications [2], and mechanistic evidence is emerging regarding the greater lipocentric versus glucocentric nature of CVD risk in patients with type 2 diabetes $[7,18]$. Insulin resistance is central to the pathogenesis of type 2 diabetes and contributes to dyslipidemia [17]. Insulin resistance is associated with increased levels of serum insulin and depletion of $\beta$-cells and results in impaired regulation of circulating lipoprotein and glucose levels [7,13]. Data suggest impairment in the ability of insulin to suppress hepatic production of large TG-rich VLDL (VLDL-TGs) in patients with type 2 diabetes results in a subsequent elevation in plasma TG levels (Figure 1) [13-15].

Impaired insulin action at the level of the adipocyte is believed to result in defective suppression of intracellular hydrolysis of TGs with the release of nonesterified (free) fatty acids (NEFAs) into the circulation [17]. The increased influx of NEFAs to the liver promotes TG synthesis and the assembly and secretion of large VLDL; this results in elevated plasma VLDL levels (hypertriglyceridemia) and postprandial hyperlipidemia that is compounded by impaired lipoprotein lipase activity - the latter regarded as independently associated with coronary artery disease. Hypertriglyceridemia can trigger thrombogenic alterations in the coagulation system. In addition, elevated VLDL-TGs reduce levels of cardioprotective HDL-C as TGs are transferred when these particles collide. The reduction in HDL-C levels is accompanied by a reduction in antioxidant and antiatherogenic activities. Of note, VLDL-enhanced TG enrichment of HDL-C and LDL-C by exchange of TG 
for cholesterol is followed by hepatic lipase-mediated hydrolysis of the TG portion, resulting in small, relatively cholesterol-poor HDL (which are subsequently catabolized and cleared from the circulation) and LDL particles [18]. When LDL particles become small and dense, they are more prone to oxidation and more readily adhere to and subsequently invade the arterial wall, contributing to atherosclerosis; small, dense LDL particles are therefore regarded as more atherogenic than their larger, more buoyant precursor [17].

Cholesterol ester transfer protein (CETP) is also known to play a pathological role in diabetic dyslipidemia, particularly in the reduction of HDL-C levels due to increased catabolism [20]. This finding has lead to the speculation that CETP inhibition may increase HDL-C levels, and several CETP inhibitors are in development. Failure of the first of these, torcetrapib, due to increased incidence of adverse cardiovascular events, has led to concerns about the utility of CETP as a therapeutic target. However, since increases in blood pressure (BP) and plasma aldosterone levels were reported with torcetrapib, it is possible that off-target effects were responsible for the adverse outcomes rather than CETP inhibition itself [21]. BP and plasma aldosterone increases have not been reported with anacetrapib - the second CETP inhibitor in development $[22,23]$.

Activation of the renin-angiotensin-aldosterone system (RAAS) can interfere with insulin signaling as well, promoting and exacerbating insulin resistance in patients with type 2 diabetes. RAAS activation increases oxidative stress, decreases nitric oxide production, and activates protein kinase signaling pathways, leading to excess generation of angiotensin II, endothelial damage, and vascular complications in patients with type 2 diabetes, resulting in an increased risk of CVD [24,25]. Inhibition of RAAS with an angiotensin-converting enzyme inhibitor reduces the risk of death from cardiovascular causes in patients with type 2 diabetes $[24,26]$.

\section{The prevalence of dyslipidemia in association with type 2 diabetes}

Data from the United States National Health and Nutritional Examination Survey (NHANES) 1999-2000 show that $<50 \%$ of 498 adults with type 2 diabetes had total cholesterol (TC) levels $<200 \mathrm{mg} / \mathrm{dL}$ despite $>50 \%$ of these patients receiving medication for dyslipidemia $[4,27]$. Furthermore, there was little difference in the proportion of patients with LDL-C $<100 \mathrm{mg} / \mathrm{dL}$ in the population with type 2 diabetes versus the nondiabetic population ( $25.3 \%$ vs $24.3 \%$, respectively). However, significantly fewer patients with type 2 diabetes had HDL-C and TG at optimal levels compared with patients without type 2 diabetes (Figure 2) [27]. Consistent with the data from NHANES 1999-2000, data from the United
Kingdom Prospective Diabetes Study (UKPDS) in 3713 newly diagnosed patients with type 2 diabetes reported that HDL-C levels were lower (by 9\% [men] and 23\% [women]) while TG levels were $50 \%$ higher in patients with type 2 diabetes than in nondiabetic patients; LDL-C values were similar (for males but higher in females) between those with and without type 2 diabetes [2]. As the pattern of elevated lipids was more pronounced in females, it was suggested to contribute to the greater cardiovascular risk in females compared with males [2]. Data from NHANES 1999-2000 showed that among patients with type 2 diabetes receiving treatment for dyslipidemia, control of LDL-C was only achieved in $29.7 \%$ of patients, and optimal levels of LDL-C, HDL-C, and TG were only achieved in $3.4 \%$ of patients; these data were comparable to those in patients with type 2 diabetes who were untreated for dyslipidemia (Figure 3) [27].

\section{Cardiovascular risk associated with dyslipidemia and treatment goals for patients with type 2 diabetes}

In SHIELD (Study to Help Improve Early evaluation and management of risk factors Leading to Diabetes), a community-based population survey conducted in the United States, a multivariate analysis of self-reported data from 22,001 patients showed that dyslipidemia was independently associated with a higher likelihood of type 2 diabetes diagnosis (odds ratio, 3.95; $P<0.0001$ ) [28]. Moreover, it is increasingly recognized that the risk of cardiovascular events is increased in patients with type 2 diabetes and that dyslipidemia is a contributing factor with often fatal outcomes [9]. Optimal management strategies have not been fully elucidated. Although the focus has largely been on lowering LDL-C levels, the benefits associated with targeting other lipids and lipoproteins are emerging.

EUROASPIRE (EUROpean Action on Secondary Prevention through Intervention to Reduce Events) was a large survey performed to assess current clinical practice in relation to reporting and management of risk factors in the secondary prevention of coronary heart disease (CHD). Data from EUROASPIRE showed a high prevalence of modifiable risk factors, including smoking, weight, hypertension, dyslipidemia, type 2 diabetes, and lack of screening in first-degree blood relatives, among patients with CHD [29].

\section{LDL-C}

The relationship between LDL-C and CVD risk is continuous over a broad range of LDL-C levels in patients with and without type 2 diabetes, and the National Cholesterol Education Program Adult Treatment Panel III (NCEP ATP III) recommends target lipid levels for patients with type 2 diabetes and dyslipidemia (Table 2) [30]. 


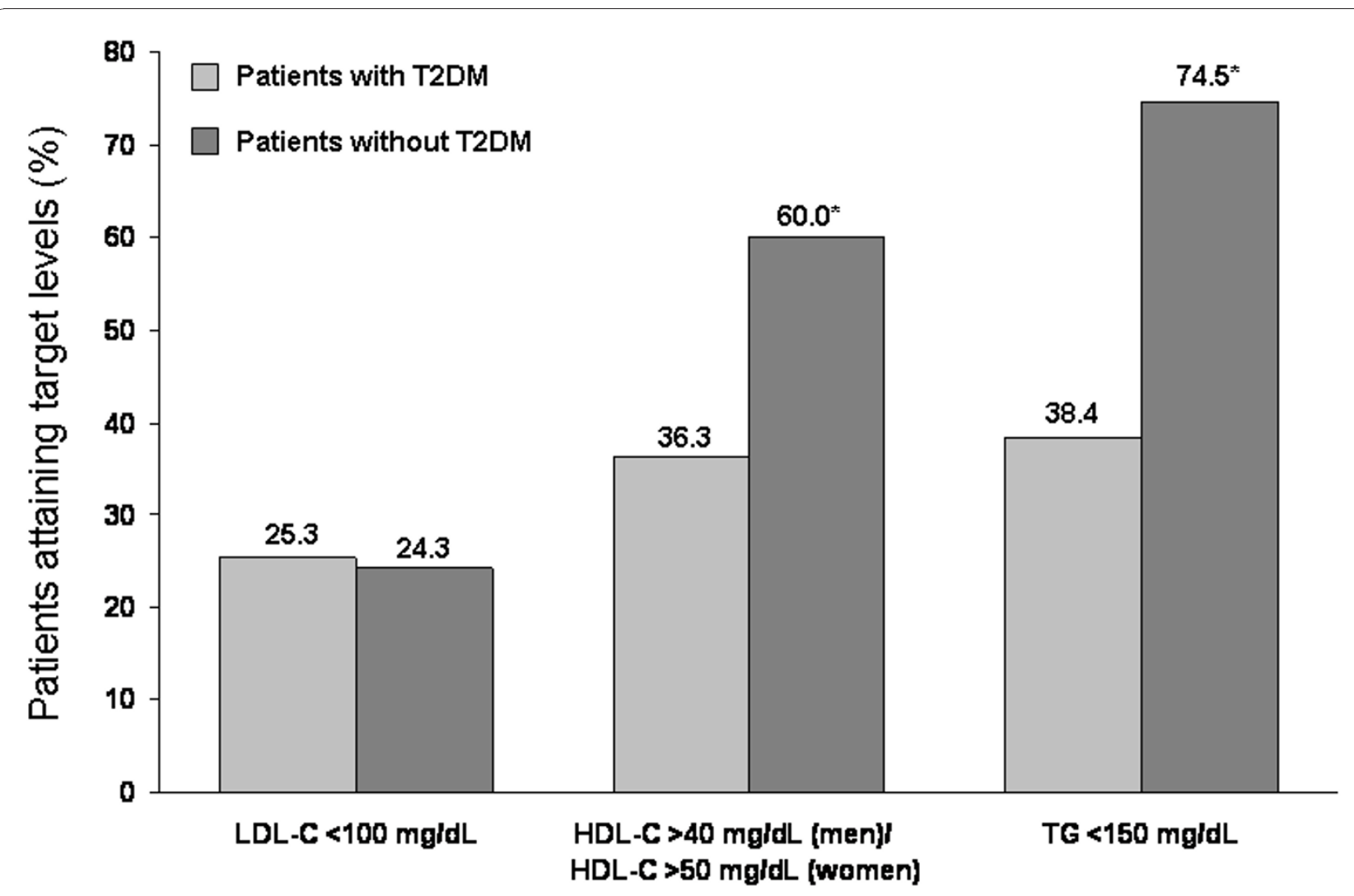

Figure 2 Prevalence of target low-density lipoprotein cholesterol (LDL-C), high-density lipoprotein cholesterol (HDL-C), and triglyceride (TG) levels for patients with and without type 2 diabetes mellitus (T2DM): National Health and Nutrition Examination Survey 1999-2000. ${ }^{*} P<0.001$ vs patients with T2DM. Reprinted from Diabetes Res Clin Pract, 70(3), Jacobs MJ, et al, 263-269, Copyright 2005, with permission from Elsevier [27].

Elevated LDL-C levels are more pathogenic in those with type 2 diabetes due to the presence of small, dense LDL particles and other potentially atherogenic lipoproteins, such as VLDL and intermediate-density lipoprotein (IDL) $[9,14,17,31]$, and data have demonstrated that lowering LDL-C levels reduces the risk for major CVD events in patients with type 2 diabetes [8]. Data from CARDS (Collaborative Atorvastatin Diabetes Study) demonstrated a clinical benefit $37 \%$ reduction in the first incidence of a major cardiovascular event; $P=$ $0.001)$ with atorvastatin in patients $(\mathrm{n}=2838)$ with type 2 diabetes whose lipid profile was not highly elevated, highlighting the importance of lipid modification for primary prevention of CVD in patients with type 2 diabetes [32]. Similarly, in the Heart Protection Study (HPS) in patients $(n=2912)$ with type 2 diabetes and no known coronary or other occlusive disease, simvastatin was associated with a $33 \%$ reduction $(P=0.0003)$ in coronary event rate over 5 years of treatment [33]. Importantly, the CVD benefits observed in CARDS and HPS were associated with a reduction in LDL-C, independent of baseline LDL-C level [8].
Further evidence of cardiovascular risk reduction with intensive control of LDL-C in patients with type 2 diabetes comes from ASCOT-LLA (Anglo-Scandinavian Cardiac Outcomes Trial-Lipid-Lowering Arm) [34]. In the cohort of 2532 patients with type 2 diabetes with well-controlled (average or below) BP and cholesterol levels, atorvastatin was associated with a reduction of $23 \%(P=0.04)$ in total major CVD events or procedures compared with placebo; corresponding reductions in TC and LDL-C levels were $17 \%$ and $27 \%$, respectively [34]. In addition, the Treating to New Targets (TNT) study demonstrated the benefits of reducing LDL-C to below currently recommended levels in higher-risk patients. In the 1501 patients with type 2 diabetes and CVD, intensive statin therapy provided an additional $25 \%$ reduction in major CVD events over 5 years $(P=0.03)$ [35]. In a meta-analysis of data from 14 randomized trials in 18,686 patients with diabetes (17,220 patients with type 2 diabetes), statin therapy was associated with a significant reduction in all-cause mortality $(P=0.02)$ per $\mathrm{mmol} / \mathrm{L}$ reduction in $\mathrm{LDL}-\mathrm{C}$, reflecting a significant reduction in vascular mortality $(P=0.008)$. Reductions 


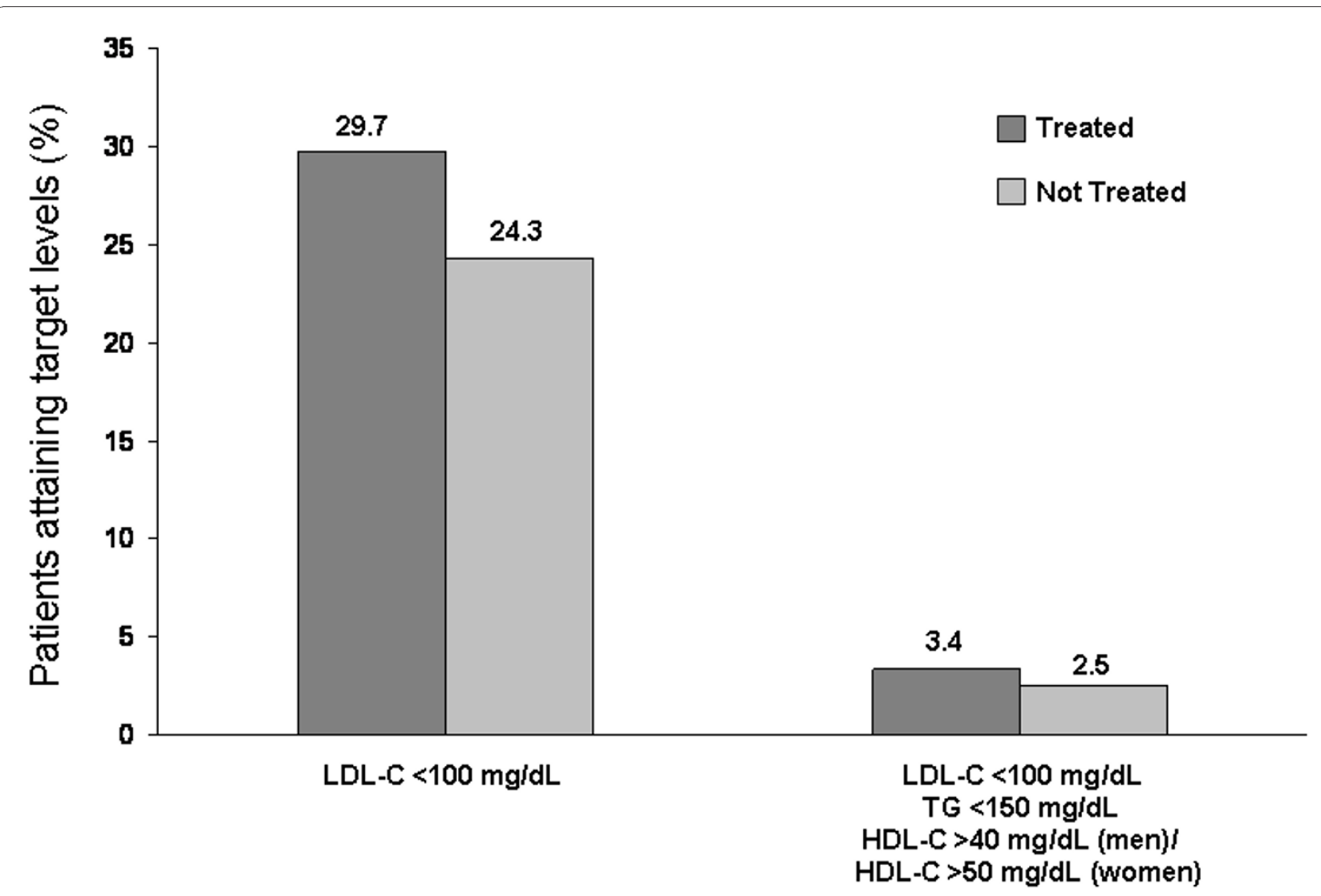

Figure 3 Prevalence of target low-density lipoprotein cholesterol (LDL-C) and combined LDL-C, high-density lipoprotein cholesterol (HDL-C) + triglyceride (TG) levels for patients with type 2 diabetes mellitus either treated or not treated for dyslipidemia: National Health and Nutrition Examination Survey 1999-2000 [27].

were seen regardless of prior history of vascular disease and other baseline characteristics and were similar to those seen in patients without diabetes [36]. These studies support recommendations from the American Diabetes Association (ADA) of LDL-C targets for patients with type 2 diabetes of $<100 \mathrm{mg} / \mathrm{dL}$ in low-risk patients and $<70 \mathrm{mg} / \mathrm{dL}$ in high-risk patients (Table 1), as well as reducing LDL-C by $30 \%$ to $40 \%$ in all patients aged > 40 years, and in all patients with overt CVD, regardless of baseline LDL-C status; these recommendations are also supported by the American Heart Association [8].

Although there appears to be almost overwhelming evidence for links between dyslipidemia and cardiovascular risk and between normalization of lipid levels and reduced cardiovascular risk, the data are not completely consistent. Positive data should be viewed in context with more negative data such as those seen in ASPEN (Atorvastatin Study for Prevention of coronary heart disease Endpoints in Non-insulin-dependent diabetes mellitus) [37]. ASPEN was a 4-year double-blind, randomized trial to assess the effect of atorvastatin on CVD prevention in 2410 patients with type 2 diabetes and normal LDL-C levels. In this study, mean LDL-C was significantly lowered with atorvastatin versus placebo $(P<0.0001)$; however, the composite primary endpoint (cardiovascular death, nonfatal cardiovascular events) and secondary individual endpoints were not significant [37]. Available data also suggest that increasing HDL-C levels alone does not reduce cardiovascular morbidity or mortality. In a meta-analysis of 108 randomized trials involving 299,310 patients at risk of cardiovascular events, changes in HDL-C did not correlate with cardiovascular outcomes or mortality, and the results support LDL-C reduction as the primary goal for lipidmodifying interventions [38].

\section{TG, HDL-C, and Non-HDL-C}

In the UKPDS, a multivariate analysis found that LDL-C was the strongest independent predictor of CVD, followed by HDL-C, while modestly elevated TG levels did not predict CVD events [6], helping to justify current national guidelines advocating LDL-C $<100 \mathrm{mg} / \mathrm{dL}$ as the primary target for the management of dyslipidemia in patients with type 2 diabetes (Table 1). Serum TG levels are a surrogate for TG-rich lipoproteins (eg, VLDL-C), 
Table 2 Classification of Lipid Levels from the National Cholesterol Education Program Expert Panel [30]

\begin{tabular}{ll}
\hline Level $(\mathbf{m g} / \mathbf{d L})$ & Classification \\
\hline TC & Desirable \\
$200-239$ & Borderline high \\
$\geq 240$ & High \\
\hline LDL-C & \\
$<100$ & Optimal \\
$100-129$ & Near or above optimal \\
$130-159$ & Borderline high \\
$160-189$ & High \\
$\geq 190$ & Very high \\
\hline VLDL-C & \\
$\leq 30$ & Normal \\
\hline HDL-C & \\
$<40$ & Low \\
$\geq 60$ & High \\
\hline$T G ~$ & \\
$<150$ & Normal \\
$150-199$ & Borderline high \\
$200-499$ & High \\
$\geq 500$ & Very high
\end{tabular}

HDL-C, high-density lipoprotein cholesterol; LDL-C, low-density lipoprotein cholesterol; TC, total cholesterol; TG, triglyceride; VLDL-C, very-low-density lipoprotein cholesterol.

and non-HDL-C (LDL-C + VLDL-C or TC - HDL-C) reflects the concentration of cholesterol within lipoprotein particles considered atherogenic [8,9]. Currently, there is no evidence to demonstrate that lowering TG levels is associated with a reduction in CVD events; as a result, treatment to reduce TG levels in patients with type 2 diabetes is of secondary importance (Table 1) [9]. While HDL-C level is a strong CVD risk predictor, clinical evidence supporting the benefits of treatment aimed at increasing HDL-C levels is modest; as a result, therapy aimed at altering HDL-C in patients with type 2 diabetes is also of secondary importance (Table 1) [9]. Although not widely adopted, the ADA/American College of Cardiology (ACC) support the NCEP ATP III recommendation to use non-HDL-C as a secondary treatment target for patients with TG levels $>200 \mathrm{mg} / \mathrm{dL}$; in these patients, the recommended non-HDL-C goal is $30 \mathrm{mg} / \mathrm{dL}$ higher than the LDL-C goal (Table 1) [9].

\section{ApoB}

The small, dense LDL particles that accompany insulin resistance provide a better assessment of the atherogenic lipoprotein load than LDL-C level. Despite continued recommendations to reduce LDL-C in all patients with type 2 diabetes, the $\mathrm{ADA} / \mathrm{ACC}$ has recognized limitations (including cost, complexity, and lack of standardized measurement techniques) in using LDL-C as a biomarker to guide therapeutic decisions for patients at high metabolic risk [9]. LDL particle concentration and apoB level appear to be more closely associated with type 2 diabetes and insulin resistance than LDL-C or non-HDL-C and may therefore be better predictors of vascular events $[9,16,39,40]$. Although it is possible to assess risk by measuring LDL particle concentration using nuclear magnetic resonance (NMR) [41], this technique is not widely available, relatively expensive, and of dubious accuracy [9]. However, given that there is one particle of apoB in each atherogenic lipoprotein particle (ie, LDL, IDL, and VLDL), quantification of apoB should capture the total burden of the most atherogenic particles $[9,16,40]$, and thus serve as a valuable marker of CVD risk [14]. Although the apoB assay has been standardized and does not require a fasting sample, it is not yet widely available. Nevertheless, secondary targets of therapy have been recommended for apoB (for patients with uncomplicated type 2 diabetes $[<90 \mathrm{mg} / \mathrm{dL}]$ and for patients with type 2 diabetes and other major risk factors $[<80 \mathrm{mg} / \mathrm{dL}]$ ) [9].

\section{ApoA-I}

Data from epidemiological, observational, and interventional studies also suggest an association between apolipoprotein A-I (apoA-I) and cardiovascular risk, indicating that assessment of apoA-I in addition to apoB may provide more accurate prediction of high cardiovascular risk than conventional lipid parameters [42]. The ratio of apoB to apoA-I has been shown to correlate with cardiovascular risk in children [43].

\section{Improving dyslipidemia in patients with type $\mathbf{2}$ diabetes}

Achievement of recommended lipid and lipoprotein targets usually requires pharmacological therapy in addition to lifestyle modifications (a low-fat/cholesterol diet and physical activity). Although aggressive LDL-C control is recommended [10], evidence-based strategies are needed to monitor the benefits and risks of pharmacotherapy aimed at surrogate markers [44] and to evaluate whether lower targets do indeed achieve better cardiovascular outcomes [45].

\section{Lipid-lowering agents \\ Statins}

Statin therapy is recommended as the initial pharmacological treatment for lowering LDL-C levels in patients with type 2 diabetes who either have overt CVD or are over 40 years old and have increased CVD risk $[8,10]$; however, even with adequate LDL-C lowering via statin therapy, CVD risk remains high in many patients $[8,9]$. The beneficial effects of statin treatment are thought to be mediated predominantly via lowering of LDL-C 
levels, although effects on HDL-C and other lipoproteins may also play a role [9]. Statin treatment lowers nonHDL-C more than apoB [40], and reaching the apoB target usually requires more intensive therapy than that required to achieve the non-HDL-C goal $[46,47]$. Common adverse events associated with statin use include gastrointestinal upset and muscle aches, although doserelated hepatoxicity and myotoxicity are the most clinically significant adverse events [48]. Caution is recommended in patients with severe renal impairment (creatinine clearance $<30 \mathrm{~mL} / \mathrm{min}$ ). Studies have shown that high-dose statin therapy is effective in achieving LDL-C goals and associated with favorable effects on lipoprotein subfractions in patients with type 2 diabetes, which may translate into clinical benefits in terms of anti-atherogenic potential and a subsequent reduction in the risk of adverse cardiovascular outcomes [49,50].

\section{Other lipid-lowering therapies}

Niacin has been used to treat dyslipidemia in patients with type 2 diabetes for over half a century [51]. Although niacin is the most effective agent for raising HDL-C levels, high doses can worsen hyperglycemia [10]. Additional adverse events associated with niacin include flushing, itching, nausea, gastrointestinal upset, hypotension, and tachycardia [48,51]. It has been suggested that combination lipid-lowering therapy (eg, a statin with a fibrate or niacin) may be necessary for patients with diabetic dyslipidemia to achieve optimal lipid levels; however, to date, such strategies have not been adequately evaluated for their long-term effect on CVD risk reduction or safety compared with lipid-lowering monotherapy [8-10]. Furthermore, the risk of myopathy is thought to be greater when niacin is used with a statin [51]. Niacin plus laropiprant - a prostaglandin $D_{2}$ receptor antagonist and antiflushing agent has been used successfully to improve the lipid profile with reduced niacin-associated flushing in patients with type 2 diabetes [52]. In 2 large randomized studies in patients with primary hypercholesterolemia or mixed dyslipidemia, the combination of niacin, laropiprant, and simvastatin significantly improved lipid parameters with a similar tolerability profile versus niacin/laropiprant alone, but with an increase in flushing and other niacin-related adverse effects versus statin alone $[53,54]$.

Ezetimibe, a selective cholesterol absorption inhibitor, is an effective lipid-lowering agent when used as monotherapy and is useful in patients who are unable to tolerate statin therapy [51]. Ezetimibe can also be used in combination with statin therapy for greater lipid-lowering efficacy. Ezetimibe plus atorvastatin, for example, can provide LDL-C lowering equivalent to that achieved with high-dose atorvastatin, but with better tolerability in some patients, and may be a useful adjunctive therapy in patients with type 2 diabetes who have demonstrated an inadequate response to statin treatment [55].

Fibrates are useful for lowering TG and non-HDL-C levels and increasing HDL-C, yet results from trials in patients with type 2 diabetes have been controversial [56]. In the FIELD (Fenofibrate Intervention and Event Lowering in Diabetes) study in 9795 patients with type 2 diabetes, fenofibrate did not significantly affect the primary endpoint, coronary event rate, relative to placebo (11\% reduction) [57]. Nevertheless, FIELD did show that combination therapy with a statin and fenofibrate is safe. Recent results from the ACCORD (Action to Control Cardiovascular Risk in Diabetes) study provided further insight into whether the combination of a statin and a fibrate is safe and provides CVD benefits beyond statin therapy alone. In this study in 5518 patients with type 2 diabetes, there was no difference between combination therapy with a statin and fibrate compared with statin therapy alone with respect to the primary outcome (nonfatal myocardial infarction, nonfatal stroke, or death from cardiovascular causes) [58]. Common adverse events associated with fibrates include gastrointestinal disturbance, rash, headache, pancreatitis, myalgia, and myotoxicity (in rare instances - and possibly more likely with gemfibrozil than with fenofibrate [59]). Adjuvant fibrate therapy is not recommended in patients with severe renal dysfunction, severe hepatic dysfunction, and preexisting gall bladder disease [48].

\section{Glucose-lowering agents}

In addition to their glucose-lowering properties, antidiabetes agents that directly improve insulin resistance may have effects on lipid levels, especially TG levels. Although there may be no effect on HDL-C levels, these agents may instead alter the ratio of lipoproteins in HDL towards more anti-atherogenic HDL particles [48]. For example, metformin has been shown to reduce LDL-C, TC, and TG levels and increase HDL-C levels [60]. Similarly, pioglitazone has been shown to reduce TG levels and increase HDL-C levels [61]. In contrast, rosiglitazone has been shown to increase LDL-C, TC, and HDL-C levels, although this thiazolidinedione does not affect TG levels [62]. A prospective study evaluating the effects of 4 months of treatment with pioglitazone or rosiglitazone in addition to statin therapy in 127 patients with type 2 diabetes showed that, despite similar findings regarding $\mathrm{HbA}_{1 \mathrm{c}}$ and weight gain (no changes from baseline in $\mathrm{HbA}_{1 \mathrm{c}}$ and similar significant weight gain in both groups at 4 months), pioglitazone, but not rosiglitazone, was associated with significant improvements in the lipid profile $(P<0.01)$ [63]. Interestingly, both thiazolidinediones have been shown to increase LDL particle size and decrease LDL oxidation conditions that impair atherosclerosis (pioglitazone 
more so than rosiglitazone) [64]. Pioglitazone has also been reported to improve HDL-C and TG parameters when used as an add-on therapy in patients with type 2 diabetes who are already receiving metformin or sulfonylurea therapy $[65,66]$ and is more effective in improving lipid and apolipoprotein levels than rosiglitazone plus sulfonylurea, in addition to ongoing statin therapy [67]. Although the use of sulfonylurea monotherapy has not been associated with significant changes in the lipid profile, the addition of acarbose to sulfonylurea therapy not only improves glycemic control, but also provides improvements in lipid parameters, particularly TG levels [68].

\section{Dual lipid- and glucose-lowering agents}

Accumulating evidence indicates that lipid and glucose homeostasis are interrelated [69]. Both are affected by bile acid-activated signaling pathways in the liver [70]. Indeed, bile acids have an established role in dietary lipid absorption and cholesterol metabolism, and are also signaling molecules that affect systemic endocrine functions through multiple signaling pathways [71]. Agents that modulate bile acids may potentially affect both cholesterol and glucose metabolism, and hence dyslipidemia and hyperglycemia, in patients with type 2 diabetes [69,71,72].

Bile acid sequestrants are established agents for LDL$\mathrm{C}$ lowering. The bile acid sequestrant colesevelam lowers LDL-C when used as monotherapy (up to $18 \%$ ) [73] and can result in reductions of up to $48 \%$ when used in combination with a statin in patients with mild-to-moderate hypercholesterolemia [74]. In addition, colesevelam is the only lipid-lowering agent approved to improve glucose levels in patients with type 2 diabetes [75]. A pilot study, GLOWS (GlucoseLowering effect of WelChol Study), showed that colesevelam significantly reduced LDL-C levels (11.7\%) and $\mathrm{HbA}_{1 \mathrm{c}}(0.5 \%)$ compared with placebo when added to existing metformin- and/or sulfonylurea-based therapy in patients with type 2 diabetes [76]. In subsequent trials, the addition of colesevelam to stable metformin, sulfonylurea-, or insulin-based therapy resulted in additional reductions in LDL-C $(12.8 \%$ to $16.7 \%)$ and $\mathrm{HbA}_{1 \mathrm{c}}(0.50 \%$ to $0.54 \%)(P<0.001$ vs placebo for all $)$ [77-79]. Consistent with a significant reduction in apoB (11.8\%) in GLOWS [76], improvements in atherogenic lipoprotein subclasses measured by NMR were also reported with colesevelam. The most significant effect with colesevelam was seen on LDL particles (15.5\% reduction vs placebo; $P=0.006$ ), primarily due to an improvement in the number of small LDL particles $(P=0.054$ vs placebo) [80]. Notably, the reduction in LDL particles was the only lipid parameter correlated with improvement in $\mathrm{HbA}_{1 \mathrm{c}}$ [80].
The use of bile acid sequestrants in patients with type 2 diabetes has been a concern due to an association with increased fasting TG levels. There was a nonsignificant increase in TGs and in TG-containing VLDL particles in association with colesevelam in GLOWS; however, there was a significant increase in TG levels in studies when colesevelam was added to sulfonylureabased therapy $(17.7 \%$ vs placebo; $P<0.001)$ and insulinbased therapy ( $21.5 \%$ vs placebo; $P<0.001)$, though not metformin-based therapy ( $4.7 \%$ vs placebo; $P=0.22$ ) [76-79]. Adverse events associated with colesevelam include gastrointestinal disturbances such as constipation, dyspepsia, and nausea [75].

The exact mechanism by which a bile acid sequestrant may improve glycemic control in patients with type 2 diabetes is not fully understood, but may involve activation of the nuclear receptors farnesoid X receptor (FXR) in the liver and intestine and TGR5 in the intestine [72,81]. FXR is a bile acid-activated nuclear receptor involved in the metabolism of cholesterol and glucose $[82,83]$. Intestinal activation of FXR modulates multiple downstream effects including those that affect glucose and lipid metabolism through regulatory activity at other sites including the liver $\mathrm{X}$ receptor, a potential glucose sensor [70]. In vitro, TGR5 has been shown to improve expression of the incretin hormone glucagonlike peptide-1 (GLP-1), which improves insulin secretion. Both colestimide and colesevelam have been shown to increase GLP-1 in patients with type 2 diabetes and hypercholesterolemia [84,85]. Further studies are needed to elucidate the mechanism(s) for bile acid sequestrant-mediated regulation of glucose control.

\section{Antihypertensive agents}

Some antihypertensive agents are known to be lipid neutral (angiotensin-converting enzyme inhibitors, calciumchannel blockers, and angiotensin II receptor blockers) or lipid friendly ( $\alpha$-blockers) [86]. In patients with type 2 diabetes and dyslipidemia, a lipid-neutral/friendly antihypertensive would be expected to be associated with greater clinical benefits than a lipid-hostile antihypertensive such as a $\beta$-blocker or thiazide diuretic [87].

\section{Dyslipidemia and renal function}

In addition to being associated with an increased risk of CVD, dyslipidemia is also associated with an increased risk of renal dysfunction (increased serum creatinine elevation and decline in glomerular filtration rate) in patients with type 2 diabetes [88-90]. Chronic renal dysfunction can increase the risk of CVD. An analysis of cardiac function in patients with type 2 diabetes and end-stage renal disease showed that significantly more patients with type 2 diabetes than without had impaired cardiac function as measured by left ventricular 
hypertrophy ( $50 \%$ vs $38 \%$, respectively; $P=0.04$ ), ischemic heart disease $(32 \%$ vs $18 \% ; P=0.003)$, and cardiac failure $(48 \%$ vs $24 \%$; $P<0.0001)$ [91]. Therefore, lowering lipid levels in patients with type 2 diabetes may improve both cardiovascular risk and renal function. Post-hoc analyses have shown that statin therapy is associated with improved renal function in patients with diabetes and those with chronic renal insufficiency and CVD [33,92]. In the MRC/BHF Heart Protection Study, simvastatin improved renal function in patients with type 2 diabetes [33]. However, it remains unclear whether the beneficial renal effects of statins are a direct result of reduced serum cholesterol levels or an as yet undefined pleiotropic effect.

\section{Conclusions}

Type 2 diabetes is associated with a characteristic atherogenic lipid pattern of elevated serum TGs, low serum HDL-C levels, and a preponderance of small, dense LDL particles. Disturbance of lipid metabolism linked to insulin resistance may be the primary event in the development of type 2 diabetes. The majority of adults in the United States with type 2 diabetes do not have optimal lipid profiles based on national guidelines. In order to reduce the risk of CVD in patients with type 2 diabetes, physicians must initiate early and effective lipid-lowering therapy. Although the first priority of treatment is to lower LDL-C in patients with type 2 diabetes, the atherogenic pattern of dyslipidemia associated with type 2 diabetes may require an advanced treatment approach that ultimately aims for full normalization of the lipid profile to decrease cardiovascular risk. Data from combined prevalence studies suggest that potentially all patients with type 2 diabetes may have an abnormal lipid profile. Despite aggressive lipid-lowering therapy, many patients with type 2 diabetes do not achieve the recommended lipid levels to reduce their CVD risk sufficiently. Adjuvant use of a bile acid sequestrant such as colesevelam, having the dual effect of improving both glycemic control and atherogenic profile in patients with type 2 diabetes, may help improve the overall management of type 2 diabetes in some patients.

\footnotetext{
Abbreviations

ACC: American College of Cardiology; ACCORD: Action to Control Cardiovascular Risk in Diabetes; ADA: American Diabetes Association; Apo: apolipoprotein; ASCOT-LLA: Anglo-Scandinavian Cardiac Outcomes TrialLipid-Lowering Arm; ASPEN: Atorvastatin Study for Prevention of coronary heart disease Endpoints in Non-insulin-dependent diabetes mellitus; BP: blood pressure; CARDS: Collaborative Atorvastatin Diabetes Study; CETP: cholesterol ester transfer protein; CHD: coronary heart disease; CVD: cardiovascular disease; EUROASPIRE: EUROpean Action on Secondary Prevention through Intervention to Reduce Events; FIELD: Fenofibrate Intervention and Event Lowering in Diabetes; FXR: farnesoid X receptor; GLOWS: Glucose-Lowering effect of WelChol Study; GLP-1: glucagon-like
}

peptide-1; HDL-C: high-density lipoprotein cholesterol; HPS: Heart Protection Study; IDL: intermediate-density lipoprotein; LDL-C: low-density lipoprotein cholesterol; NCEP ATP III: National Cholesterol Education Program Adult Treatment Panel III; NEFA: nonesterified (free) fatty acid; NHANES: United States National Health and Nutritional Examination Survey; NMR: nuclear magnetic resonance; Non-HDL-C: non-high-density lipoprotein cholesterol; RAAS: renin-angiotensin-aldosterone system; SHIELD: Study to Help Improve Early evaluation and management of risk factors Leading to Diabetes; TC: total cholesterol; TG: triglyceride; TNT: Treating to New Targets; UKPDS: United Kingdom Prospective Diabetes Study; VLDL: very-low-density lipoprotein cholesterol.

\section{Acknowledgements}

Medical writing services for editorial assistance provided by Luana Atherly, PhD, and Nila Bhana, MSc, of inScience Communications, a Wolters Kluwer business, were funded by Daiichi Sankyo, Inc

\section{Authors' contributions}

KV has read and approved the final manuscript.

\section{Competing interests}

$\mathrm{KV}$ has received honoraria from Daiichi Sankyo, Inc. as a member of their advisory board.

Received: 18 November 2010 Accepted: 20 December 2010 Published: 20 December 2010

\section{References}

1. Centers for Disease Control and Prevention: National diabetes fact sheet. [http://www.cdc.gov/diabetes/pubs/pdf/ndfs_2007.pdf].

2. United Kingdom Prospective Diabetes Study: Plasma lipids and lipoproteins at diagnosis of NIDDM by age and sex (UKPDS 27). Diabetes Care 1997, 20:1683-1687.

3. Kannel WB, McGee DL: Diabetes and cardiovascular disease. The Framingham study. JAMA 1979, 241:2035-2038.

4. Saydah SH, Fradkin J, Cowie CC: Poor control of risk factors for vascular disease among adults with previously diagnosed diabetes. JAMA 2004, 291:335-342.

5. Stratton IM, Adler Al, Neil HA, Matthews DR, Manley SE, Cull CA, Hadden D, Turner RC, Holman RR: Association of glycaemia with macrovascular and microvascular complications of type 2 diabetes (UKPDS 35): prospective observational study. BMJ 2000, 321:405-412.

6. Turner RC, Millns H, Neil HA, Stratton IM, Manley SE, Matthews DR, Holman RR: Risk factors for coronary artery disease in non-insulin dependent diabetes mellitus: United Kingdom Prospective Diabetes Study (UKPDS 23). BMJ 1998, 316:823-828.

7. Farmer JA: Diabetic dyslipidemia and atherosclerosis: evidence from clinical trials. Curr Diab Rep 2008, 8:71-77.

8. Goff DC Jr, Gerstein HC, Ginsberg HN, Cushman WC, Margolis KL, Byington RP, Buse JB, Genuth S, Probstfield JL, Simons-Morton DG: Prevention of cardiovascular disease in persons with type 2 diabetes mellitus: current knowledge and rationale for the Action to Control Cardiovascular Risk in Diabetes (ACCORD) trial. Am J Cardiol 2007, 99:4i-20i.

9. Brunzell JD, Davidson M, Furberg CD, Goldberg RB, Howard BV, Stein JH, Witztum JL: Lipoprotein management in patients with cardiometabolic risk: consensus statement from the American Diabetes Association and the American College of Cardiology Foundation. Diabetes Care 2008, 31:811-822.

10. American Diabetes Association: Standards of medical care in diabetes2009. Diabetes Care 2009, 32(Suppl 1):S13-S61

11. Stamler J, Vaccaro O, Neaton JD, Wentworth D: Diabetes, other risk factors, and 12-yr cardiovascular mortality for men screened in the Multiple Risk Factor Intervention Trial. Diabetes Care 1993, 16:434-444.

12. Grundy SM, Cleeman Jl, Merz CN, Brewer HB Jr, Clark LT, Hunninghake DB, Pasternak RC, Smith SC Jr, Stone NJ: Implications of recent clinical trials for the National Cholesterol Education Program Adult Treatment Panel III guidelines. Circulation 2004, 110:227-239.

13. Adiels M, Olofsson SO, Taskinen MR, Boren J: Diabetic dyslipidaemia. Cur Opin Lipidol 2006, 17:238-246 
14. Adiels M, Olofsson SO, Taskinen MR, Boren J: Overproduction of very lowdensity lipoproteins is the hallmark of the dyslipidemia in the metabolic syndrome. Arterioscler Thromb Vasc Biol 2008, 28:1225-1236.

15. Taskinen MR: Type 2 diabetes as a lipid disorder. Curr Mol Med 2005, 5:297-308.

16. Garvey WT, Kwon S, Zheng D, Shaughnessy S, Wallace P, Hutto A, Pugh K, Jenkins AJ, Klein RL, Liao Y: Effects of insulin resistance and type 2 diabetes on lipoprotein subclass particle size and concentration determined by nuclear magnetic resonance. Diabetes 2003, 52:453-462.

17. Krentz AJ: Lipoprotein abnormalities and their consequences for patients with type 2 diabetes. Diabetes Obes Metab 2003, 5(Suppl 1):S19-S27.

18. Solano MP, Goldberg RB: Management of dyslipidemia in diabetes. Cardiol Rev 2006, 14:125-135.

19. United Kingdom Prospective Diabetes Study: Intensive blood-glucose control with sulphonylureas or insulin compared with conventional treatment and risk of complications in patients with type 2 diabetes (UKPDS 33). UK Prospective Diabetes Study (UKPDS) Group. Lancet 1998, 352:837-853.

20. de Vries R, Borggreve SE, Dullaart RP: Role of lipases, lecithin: cholesterol acyltransferase and cholesteryl ester transfer protein in abnormal high density lipoprotein metabolism in insulin resistance and type 2 diabetes mellitus. Clin Lab 2003, 49:601-613.

21. Forrest MJ, Bloomfield D, Briscoe RJ, Brown PN, Cumiskey AM, Ehrhart J, Hershey JC, Keller WJ, Ma X, McPherson HE, Messina E, Peterson LB, SharifRodriguez W, Siegl PK, Sinclair PJ, Sparrow CP, Stevenson AS, Sun SY, Tsai C, Vargas H, Walker M, West SH, White V, Woltmann RF: Torcetrapib-induced blood pressure elevation is independent of CETP inhibition and is accompanied by increased circulating levels of aldosterone. $\mathrm{Br} J$ Pharmacol 2008, 154:1465-1473.

22. Bloomfield D, Carlson GL, Sapre A, Tribble D, McKenney JM, Littlejohn TW, Sisk CM, Mitchel Y, Pasternak RC: Efficacy and safety of the cholesteryl ester transfer protein inhibitor anacetrapib as monotherapy and coadministered with atorvastatin in dyslipidemic patients. Am Heart $J$ 2009, 157:352-360 e352.

23. Masson D: Anacetrapib, a cholesterol ester transfer protein (CETP) inhibitor for the treatment of atherosclerosis. Curr Opin Investig Drugs 2009, 10:980-987.

24. Wang CC, Goalstone ML, Draznin B: Molecular mechanisms of insulin resistance that impact cardiovascular biology. Diabetes 2004, 53:2735-2740

25. Coccheri S: Approaches to prevention of cardiovascular complications and events in diabetes mellitus. Drugs 2007, 67:997-1026.

26. Yusuf S, Sleight P, Pogue J, Bosch J, Davies R, Dagenais G: Effects of an angiotensin-converting-enzyme inhibitor, ramipril, on cardiovascular events in high-risk patients. The Heart Outcomes Prevention Evaluation Study Investigators. N Engl J Med 2000, 342:145-153.

27. Jacobs MJ, Kleisli T, Pio JR, Malik S, L'Italien GJ, Chen RS, Wong ND: Prevalence and control of dyslipidemia among persons with diabetes in the United States. Diabetes Res Clin Pract 2005, 70:263-269.

28. Bays HE, Bazata DD, Clark NG, Gavin JR, Green AJ, Lewis SJ, Reed ML, Stewart W, Chapman RH, Fox KM, Grandy S: Prevalence of self-reported diagnosis of diabetes mellitus and associated risk factors in a national survey in the US population: SHIELD (Study to Help Improve Early evaluation and management of risk factors Leading to Diabetes). BMC Public Health 2007, 7:277.

29. EUROASPIRE. A European Society of Cardiology survey of secondary prevention of coronary heart disease: principal results. EUROASPIRE Study Group: European Action on Secondary Prevention through Intervention to Reduce Events. Eur Heart J 1997, 18:1569-1582.

30. National Cholesterol Education Program Expert Panel: Executive Summary of the Third Report of The National Cholesterol Education Program (NCEP) Expert Panel on Detection, Evaluation, and Treatment of High Blood Cholesterol in Adults (Adult Treatment Panel III). JAMA 2001, 285:2486-2497.

31. Superko HR: Small, dense, low-density lipoprotein and atherosclerosis. Curr Atheroscler Rep 2000, 2:226-231.

32. Colhoun HM, Betteridge DJ, Durrington PN, Hitman GA, Neil HA, Livingstone SJ, Thomason MJ, Mackness Ml, Charlton-Menys V, Fuller JH: Primary prevention of cardiovascular disease with atorvastatin in type 2 diabetes in the Collaborative Atorvastatin Diabetes Study (CARDS): multicentre randomised placebo-controlled trial. Lancet 2004, 364:685-696.

33. Collins R, Armitage J, Parish S, Sleigh P, Peto R: MRC/BHF Heart Protection Study of cholesterol-lowering with simvastatin in 5963 people with diabetes: a randomised placebo-controlled trial. Lancet 2003, 361:2005-2016.

34. Sever PS, Poulter NR, Dahlof B, Wedel H, Collins R, Beevers G, Caulfield M, Kjeldsen SE, Kristinsson A, Mclnnes GT, Mehlsen J, Nieminen M, O'Brien E, Ostergren J: Reduction in cardiovascular events with atorvastatin in 2,532 patients with type 2 diabetes: Anglo-Scandinavian Cardiac Outcomes Trial-lipid-lowering arm (ASCOT-LLA). Diabetes Care 2005, 28:1151-1157.

35. Shepherd J, Barter P, Carmena R, Deedwania P, Fruchart JC, Haffner S, Hsia J, Breazna A, LaRosa J, Grundy S, Waters D: Effect of lowering LDL cholesterol substantially below currently recommended levels in patients with coronary heart disease and diabetes: the Treating to New Targets (TNT) study. Diabetes Care 2006, 29:1220-1226.

36. Kearney PM, Blackwell L, Collins R, Keech A, Simes J, Peto R, Armitage J, Baigent C: Efficacy of cholesterol-lowering therapy in 18,686 people with diabetes in 14 randomised trials of statins: a meta-analysis. Lancet 2008, 371:117-125.

37. Knopp RH, d'Emden M, Smilde JG, Pocock SJ: Efficacy and safety of atorvastatin in the prevention of cardiovascular end points in subjects with type 2 diabetes: the Atorvastatin Study for Prevention of Coronary Heart Disease Endpoints in non-insulin-dependent diabetes mellitus (ASPEN). Diabetes Care 2006, 29:1478-1485.

38. Briel M, Ferreira-Gonzalez I, You JJ, Karanicolas PJ, AkI EA, Wu P, Blechacz B, Bassler D, Wei X, Sharman A, Whitt I, Alves da Silva S, Khalid Z, Nordmann AJ, Zhou Q, Walter SD, Vale N, Bhatnagar N, O'Regan C, Mills EJ, Bucher HC, Montori VM, Guyatt GH: Association between change in high density lipoprotein cholesterol and cardiovascular disease morbidity and mortality: systematic review and meta-regression analysis. BMJ 2009, 338:b92.

39. Sattar N, Williams K, Sniderman AD, D'Agostino R Jr, Haffner SM: Comparison of the associations of apolipoprotein $B$ and non-highdensity lipoprotein cholesterol with other cardiovascular risk factors in patients with the metabolic syndrome in the Insulin Resistance Atherosclerosis Study. Circulation 2004, 110:2687-2693.

40. Sniderman AD, Furberg CD, Keech A, Roeters van Lennep JE, Frohlich J, Jungner I, Walldius G: Apolipoproteins versus lipids as indices of coronary risk and as targets for statin treatment. Lancet 2003, 361:777-780.

41. Cromwell WC, Otvos JD: Low-density lipoprotein particle number and risk for cardiovascular disease. Curr Atheroscler Rep 2004, 6:381-387.

42. Andrikoula M, McDowell IF: The contribution of $A p o B$ and ApoA1 measurements to cardiovascular risk assessment. Diabetes Obes Metab 2008, 10:271-278.

43. Sellers EA, Singh GR, Sayers SM: Apo-B/Al ratio identifies cardiovascular risk in childhood: the Australian Aboriginal Birth Cohort study. Diab Vasc Dis Res 2009, 6:94-99.

44. Krumholz HM, Lee TH: Redefining quality-implications of recent clinical trials. N Engl J Med 2008, 358:2537-2539.

45. Peterson ED, Wang TY: The great debate of 2008-how low to go in preventive cardiology? JAMA 2008, 299:1718-1720

46. Stein EA, Sniderman A, Laskarzewski P: Assessment of reaching goal in patients with combined hyperlipidemia: low-density lipoprotein cholesterol, non-high-density lipoprotein cholesterol, or apolipoprotein B. Am J Cardiol 2005, 96:36K-43K, discussion 34K-35K

47. Ballantyne CM, Bertolami M, Hernandez Garcia HR, Nul D, Stein EA, Theroux P, Weiss R, Cain VA, Raichlen JS: Achieving LDL cholesterol, nonHDL cholesterol, and apolipoprotein B target levels in high-risk patients: Measuring Effective Reductions in Cholesterol Using Rosuvastatin therapY (MERCURY) II. Am Heart J 2006, 151(975):e971-e979.

48. Moon YS, Kashyap ML: Pharmacologic treatment of type 2 diabetic dyslipidemia. Pharmacotherapy 2004, 24:1692-1713.

49. High-dose atorvastatin therapy achieves $25 \%$ reduction in CV events in TNT substudy of diabetic patients. Cardiovasc J S Afr 2006, 17:206-207.

50. Lawrence JM, Reid J, Taylor GJ, Stirling C, Reckless JP: The effect of high dose atorvastatin therapy on lipids and lipoprotein subfractions in overweight patients with type 2 diabetes. Atherosclerosis 2004, 174:141-149. 
51. Nesto RW: Beyond low-density lipoprotein: addressing the atherogenic lipid triad in type 2 diabetes mellitus and the metabolic syndrome. Am J Cardiovasc Drugs 2005, 5:379-387.

52. Lauring B, Dishy V, Luo WL, Laterza O, Patterson J, Cote J, Chao A, Larson P, Gutierrez M, Wagner JA, Lai E: Laropiprant in combination with extendedrelease niacin does not alter urine 11-dehydrothromboxane B2, a marker of in vivo platelet function, in healthy, hypercholesterolemic, and diabetic subjects. J Clin Pharmacol 2009, 49:1426-1435.

53. Shah S, Ceska R, Gil-Extremera B, Paolini JF, Giezek H, Vandormael K, Mao A, McCrary Sisk C, Maccubbin D: Efficacy and safety of extended-release niacin/laropiprant plus statin vs. doubling the dose of statin in patients with primary hypercholesterolaemia or mixed dyslipidaemia. Int J Clin Pract 2010, 64:727-738.

54. Gleim G, Liu N, Thompson-Bell S: Lipid-altering efficacy and safety profile of co-administered extended release niacin/laropiprant and simvastatin in patients with dyslipidemia [abstract 683]. Circulation 2007, 116:127.

55. Ballantyne CM, Houri J, Notarbartolo A, Melani L, Lipka LJ, Suresh R, Sun S, LeBeaut AP, Sager PT, Veltri EP: Effect of ezetimibe coadministered with atorvastatin in 628 patients with primary hypercholesterolemia: a prospective, randomized, double-blind trial. Circulation 2003, 107:2409-2415.

56. Colhoun H: After FIELD: should fibrates be used to prevent cardiovascular disease in diabetes? Lancet 2005, 366:1829-1831.

57. Keech A, Simes RJ, Barter P, Best J, Scott R, Taskinen MR, Forder P, Pillai A, Davis T, Glasziou P, Drury P, Kesaniemi YA, Sullivan D, Hunt D, Colman P, d'Emden M, Whiting M, Ehnholm C, Laakso M: Effects of long-term fenofibrate therapy on cardiovascular events in 9795 people with type 2 diabetes mellitus (the FIELD study): randomised controlled trial. Lancet 2005, 366:1849-1861.

58. Ginsberg HN, Elam MB, Lovato LC, Crouse JR, Leiter LA, Linz P, Friedewald WT, Buse JB, Gerstein HC, Probstfield J, Grimm RH, Ismail-Beigi F, Bigger JT, Goff DC Jr, Cushman WC, Simons-Morton DG, Byington RP: Effects of combination lipid therapy in type 2 diabetes mellitus. $N$ Engl J Med 2010, 362:1563-1574.

59. Prueksaritanont T, Tang C, Qiu Y, Mu L, Subramanian R, Lin JH: Effects of fibrates on metabolism of statins in human hepatocytes. Drug Metab Dispos 2002, 30:1280-1287.

60. Glucophage (metformin hydrochloride tablets) prescribing information Bristol-Myers Squibb Company: Princeton, NJ; 2009 [http://packageinserts. bms.com/pi/pi_glucophage.pdf].

61. ACTOS (pioglitazone hydrochloride tablets) prescribing information. Takeda Pharmaceuticals America, Inc.: Deerfield, IL; 2009 [http://www.actos. com/actospro/prescribinginfo.aspx].

62. Avandia (rosiglitazone maleate tablets) prescribing information GlaxoSmithKline: Research Triangle Park, NC; 2008 [http://us.gsk.com/ products/assets/us_avandia.pdf].

63. Khan MA, St Peter JV, Xue JL: A prospective, randomized comparison of the metabolic effects of pioglitazone or rosiglitazone in patients with type 2 diabetes who were previously treated with troglitazone. Diabetes Care 2002, 25:708-711.

64. Deeg MA, Buse JB, Goldberg RB, Kendall DM, Zagar AJ, Jacober SJ, Khan MA, Perez AT, Tan MH: Pioglitazone and rosiglitazone have different effects on serum lipoprotein particle concentrations and sizes in patients with type 2 diabetes and dyslipidemia. Diabetes Care 2007, 30:2458-2464

65. Comaschi M, Corsi A, Di Pietro C, Bellatreccia A, Mariz S: The effect of pioglitazone as add-on therapy to metformin or sulphonylurea compared to a fixed-dose combination of metformin and glibenclamide on diabetic dyslipidaemia. Nutr Metab Cardiovasc Dis 2008, 18:373-379.

66. Kipnes MS, Krosnick A, Rendell MS, Egan JW, Mathisen AL, Schneider RL: Pioglitazone hydrochloride in combination with sulfonylurea therapy improves glycemic control in patients with type 2 diabetes mellitus: a randomized, placebo-controlled study. Am J Med 2001, 111:10-17.

67. Berhanu P, Kipnes MS, Khan MA, Perez AT, Kupfer SF, Spanheimer RC, Demissie S, Fleck PR: Effects of pioglitazone on lipid and lipoprotein profiles in patients with type 2 diabetes and dyslipidaemia after treatment conversion from rosiglitazone while continuing stable statin therapy. Diab Vasc Dis Res 2006, 3:39-44.

68. Reaven GM, Lardinois CK, Greenfield MS, Schwartz HC, Vreman HJ: Effect of acarbose on carbohydrate and lipid metabolism in NIDDM patients poorly controlled by sulfonylureas. Diabetes Care 1990, 13(Suppl 3):32-36
69. Reasner CA: Reducing cardiovascular complications of type 2 diabetes by targeting multiple risk factors. J Cardiovasc Pharmacol 2008, 52:136-144.

70. Houten SM, Watanabe M, Auwerx J: Endocrine functions of bile acids. EMBO J 2006, 25:1419-1425.

71. Bays HE, Goldberg RB: The 'forgotten' bile acid sequestrants: is now a good time to remember? Am J Ther 2007, 14:567-580.

72. Goldfine AB: Modulating LDL cholesterol and glucose in patients with type 2 diabetes mellitus: targeting the bile acid pathway. Curr Opin Cardiol 2008, 23:502-511.

73. Insull W Jr, Toth P, Mullican W, Hunninghake D, Burke S, Donovan JM, Davidson $\mathrm{MH}$ : Effectiveness of colesevelam hydrochloride in decreasing LDL cholesterol in patients with primary hypercholesterolemia: a 24week randomized controlled trial. Mayo Clin Proc 2001, 76:971-982.

74. Hunninghake D, Insull W Jr, Toth P, Davidson D, Donovan JM, Burke SK: Coadministration of colesevelam hydrochloride with atorvastatin lowers LDL cholesterol additively. Atherosclerosis 2001, 158:407-416.

75. Welchol (colesevelam $\mathrm{HCl}$ ) prescribing information. Daiichi Sankyo, Inc: Parsippany, NJ; 2009 [http://www.welchol.com/pdf/Welchol_PI.pdf].

76. Zieve FJ, Kalin MF, Schwartz SL, Jones MR, Bailey WL: Results of the glucose-lowering effect of WelChol study (GLOWS): a randomized, double-blind, placebo-controlled pilot study evaluating the effect of colesevelam hydrochloride on glycemic control in subjects with type 2 diabetes. Clin Ther 2007, 29:74-83.

77. Bays HE, Goldberg RB, Truitt KE, Jones MR: Colesevelam hydrochloride therapy in patients with type 2 diabetes mellitus treated with metformin: glucose and lipid effects. Arch Intern Med 2008, 168:1975-1983.

78. Fonseca VA, Rosenstock J, Wang AC, Truitt KE, Jones MR: Colesevelam HCl improves glycemic control and reduces LDL cholesterol in patients with inadequately controlled type 2 diabetes on sulfonylurea-based therapy. Diabetes Care 2008, 31:1479-1484

79. Goldberg RB, Fonseca VA, Truitt KE, Jones MR: Efficacy and safety of colesevelam in patients with type 2 diabetes mellitus and inadequate glycemic control receiving insulin-based therapy. Arch Intern Med 2008, 168:1531-1540.

80. Rosenson RS, Abby SL, Jones MR: Colesevelam $\mathrm{HCl}$ effects on atherogenic lipoprotein subclasses in subjects with type 2 diabetes. Atherosclerosis 2009, 204:342-344

81. Staels B, Kuipers F: Bile acid sequestrants and the treatment of type 2 diabetes mellitus. Drugs 2007, 67:1383-1392.

82. Claudel T, Staels B, Kuipers F: The Farnesoid X receptor: a molecular link between bile acid and lipid and glucose metabolism. Arterioscler Thromb Vasc Biol 2005, 25:2020-2030.

83. Staels B: A review of bile acid sequestrants: potential mechanism(s) for glucose-lowering effects in type 2 diabetes mellitus. Postgrad Med 2009, 121:25-30.

84. Suzuki T, Oba K, Igari Y, Matsumura N, Watanabe K, Futami-Suda S, Yasuoka H, Ouchi M, Suzuki K, Kigawa Y, Nakano H: Colestimide lowers plasma glucose levels and increases plasma glucagon-like PEPTIDE-1 (736) levels in patients with type 2 diabetes mellitus complicated by hypercholesterolemia. J Nippon Med Sch 2007, 74:338-343.

85. Beysen C, Deines KC, Tsang EL, Murphy EJ, Chan M, Edmonds JM, Neese RA, Hellerstein MK: Colesevelam $\mathrm{HCl}$ improves glucose metabolism and increases plasma glucagon-like peptide 1 and glucose-dependent insulinotropic polypeptide concentrations in subjects with type 2 diabetes. European Association for the Study of Diabetes Annual Meeting Vienna, Austria; 2009

86. Papadakis JA, Ganotakis ES, Jagroop IA, Mikhailidis DP, Winder AF: Effect of hypertension and its treatment on lipid, lipoprotein(a), fibrinogen, and bilirubin levels in patients referred for dyslipidemia. Am J Hypertens 1999, 12:673-681.

87. Milionis HJ, Liberopoulos EN, Achimastos A, Elisaf MS, Mikhailidis DP: Statins: another class of antihypertensive agents? J Hum Hypertens 2006 20:320-335.

88. Cases A, Coll E: Dyslipidemia and the progression of renal disease in chronic renal failure patients. Kidney Int Supp/ 2005, S87-S93.

89. Schaeffner ES, Kurth T, Curhan GC, Glynn RJ, Rexrode KM, Baigent C, Buring JE, Gaziano JM: Cholesterol and the risk of renal dysfunction in apparently healthy men. J Am Soc Nephrol 2003, 14:2084-2091.

90. Ravid M, Brosh D, Ravid-Safran D, Levy Z, Rachmani R: Main risk factors for nephropathy in type 2 diabetes mellitus are plasma cholesterol levels, 
mean blood pressure, and hyperglycemia. Arch Intern Med 1998, 158:998-1004.

91. Foley RN, Culleton BF, Parfrey PS, Harnett JD, Kent GM, Murray DC, Barre PE: Cardiac disease in diabetic end-stage renal disease. Diabetologia 1997, 40:1307-1312

92. Tonelli M, Moye L, Sacks FM, Cole T, Curhan GC: Effect of pravastatin on loss of renal function in people with moderate chronic renal insufficiency and cardiovascular disease. J Am Soc Nephrol 2003, $14: 1605-1613$

doi:10.1186/1476-511X-9-144

Cite this article as: Vijayaraghavan: Treatment of dyslipidemia in patients with type 2 diabetes. Lipids in Health and Disease 2010 9:144.

Submit your next manuscript to BioMed Central and take full advantage of:

- Convenient online submission

- Thorough peer review

- No space constraints or color figure charges

- Immediate publication on acceptance

- Inclusion in PubMed, CAS, Scopus and Google Scholar

- Research which is freely available for redistribution

Submit your manuscript at www.biomedcentral.com/submit 